\title{
The psychological impact of COVID-19 and the subsequent social isolation on the general population of Karnataka, India
}

\author{
Mohammed Zaid Jaffar H. Desai ${ }^{1^{*}}$, Atiqur Rahman Khan², Rutuja Kulkarni ${ }^{1}$, Bhoomika Hegde ${ }^{1}$
}

\begin{abstract}
Background: The COVID-19 pandemic has various unfavorable effects on individuals and the community. This study aims to assess the psychological impact of the COVID-19 epidemic and the subsequent social isolation on the general population of Karnataka, India.
\end{abstract}

Methods: A web-based cross-sectional survey was conducted in Karnataka from 8 to 14 April 2020 using the snowball technique. The psychological impact was assessed with the help of the nine-item Patient Health Questionnaire-9 (PHQ-9) and seven-item General Anxiety Disorder-7 (GAD-7) questionnaires. IBM SPSS Statistics Subscription version 16.0 was recruited to analyze the data. Descriptive (Mean + Standard Deviation) and bivariate (Pearson chi-square and ANOVA tests) analysis used to present data with the significance level set at less than 0.05 .

Results: This study included 1537 participants from 26 cities in Karnataka. About two-thirds of the respondents were undergraduate students $(951,61.9 \%)$, females $(768,50.0 \%)$, and $40.1 \%$ stayed about $15-20$ days in social isolation. The prevalence of depression was $47.0 \%$, and anxiety was $41.5 \%$, respectively, among the surveyed sample. After the analysis, the age group 21-30 year old $(P<0.001)$, females $P<0.001)$, urban residents $(P=$ $0.021)$, and the students $(P p<0.001)$ were significant for depression. However, only the age group 31-40 years was found to be more susceptible to anxiety.

Conclusion: As important as addressing the psychological effects, knowing people at risk of developing mental illnesses will contribute effectively to providing appropriate psychological rehabilitation programs at the right time.

Keywords: COVID-19, Pandemic, Social Isolation, Depression, Anxiety, Karnataka, India

\section{Background}

The Novel coronavirus outbreak was first reported in Wuhan, China, in November 2019 [1]. The average incubation period of the virus is estimated to be 5.2 days, with significant variation among patients, and it may be capable of asymptomatic spread. Symptoms of infection include fever, chills, cough, coryza, sore throat, breathing difficulty, myalgia, nausea, vomiting, and diarrhea [2]. Since the virus has been reported, it has spread globally and has been declared a 'Pandemic' on 11th March 2020 by the World Health Organization [3]. As of April 13, 2020, there are 9205 confirmed cases and 331 deaths in India [4]. However, the first case was confirmed on the 9th of March.

*Correspondence: zaiddesai99@yahoo.com

${ }^{1}$ Department of Community Medicine, Undergraduate, Belagavi Institute of Medical Sciences, Belagavi, Karnataka, India

A full list of author information is available at the end of the article.
2020 in Karnataka, India [5]. Owing to its high infectivity rate, the government imposed a nationwide lockdown on 23rd March 2020 for 21 days, which called for strict isolation and social distancing [6]. With a population of over a billion people, the country's situation can deteriorate very rapidly. The virus has a crippling effect on the health and economy and harms the mental health status due to widespread fear instilled by its rampant spread. Moreover, the pandemic's continued spread, the delay in resuming school life, the closure of public places, and other unnecessary services are expected to affect the citizens' mental health.

The world appeared flustered and unprepared for this pandemic [7]. This worldwide pandemic has brought a risk of death from viral infection and created a sense of restlessness and unbearable psychological pressure to people worldwide. Steptoe et al. [8] found that social isolation and loneliness predicted mortality over seven years of follow-up in a sample of older men and women. Recently, Cao et al. [9] indicated that 
$0.9 \%$ of the surveyed students in China experienced severe anxiety, $2.7 \%$ moderate anxiety, and $21.3 \%$ mild anxiety due to the novel coronavirus. Taylor et al. [10] reported that in older adults, social isolation has the potential to cause depression and psychological distress.

The authors also found about $5.0 \%$ of subjects were objectively isolated from friends and family, and less than $1.0 \%$ had been subjectively isolated. Sim et al. [11] found that SARS has significantly associated with psychiatric (22.9\%) and posttraumatic morbidities $(25.8 \%)$, respectively. A sense of panic has been instilled in the people due to the COVID-19 pandemic, which necessitates the need to address the community's mental health status as a whole [2].

This study aims to determine the psychological impact of COVID-19 and the social isolation imposed during the pandemic of COVID-19 among Karnataka's population in southwest India.

\section{Methods}

Study design

A web-based cross-sectional study was designed to assess the psychological impact of novel coronavirus and social isolation. The data was collected using the snowball technique [12] among the people of Karnataka state from 8 to 14 April 2020. Karnataka state is located in southwest India with Arabian Sea coastlines and approximately 66.8 million people [13].

\section{Inclusion and exclusion criteria}

All Indian people aged ten years and more, residing in Karnataka state, have access to the internet (social media platforms and email), willing to participate and can understand the questions in the English language given in the online survey have been included. Simultaneously, the non-Indian or the Indian people residing out of Karnataka, age less than ten years and not willing to participate, have been excluded. Moreover, at the end of the questionnaire, the participant was questioned whether they were suffering from mental issues. However, other physical ailments/disabilities/comorbidities were not considered.

\section{Sample Size}

Given Karnataka's population is 66.8 million, the larger representative sample size is needed to increase the validity and generalizability of the study. The sample size calculator arrived at 1537 participants, using a margin of error of $\pm 2.5 \%$, confidence level of $95 \%$, and $50 \%$ response distribution [14].

\section{Study questionnaire}

A pre-structured questionnaire was formed using Google Forms and was circulated on social media platforms like WhatsApp and Instagram, which had three sections:

Section I: Personal details of the participants (age, sex, residence, occupation), number of days that they were in isolation, and the number of people whom they resided with.

Section II: Consists of the standard General Anxiety Disorder-7 (GAD-7) questionnaire. GAD-7 has seven items used to examine the participant's symptoms over the last two weeks.
Responses were given on a 4-item Likert rating scale ranging from 0 (not at all) to 3 (almost every day). The total score ranges from 0 to 21 , indicating the severity of anxiety in three levels (mild/moderate/severe) depending on the score [15]. The GAD-7 has demonstrated excellent internal consistency [16].

Section III: Consists of the standard Patient Health Questionnaire-9 (PHQ-9) questionnaire. PHQ-9 is a reliable tool to diagnose and measure the severity of depression according to the Diagnostic and Statistical Manual of Mental Disorders, Fifth Edition (DSM-5). Responses given in a score ranged between "0" (not at all) to "3" (nearly every day) [17].

Statistical analysis

Data collected were analyzed using the Statistical Package for Social Science (SPSS) program version 20.0 (SPSS Inc., Chicago IL, USA). Frequency distribution and descriptive statistics (Mean Standard Deviation) of socio-demographic variables (age, sex, location, occupation) and the number of days spent in social isolation, and the number of people isolated were obtained to provide the sample profile. Furthermore, Chisquare tests and ANOVA tests were used in the bivariate analysis concerning the severity of the seven-item GAD-7 and the nine-item PHQ- 9. An alpha level of $\mathrm{p}<0.05$ is considered to be statistically significant.

\section{Results}

Characteristic of respondents

Out of 1537 participants, half of them were females (768, $50.0 \%)$, undergraduate students $(951,61.9 \%)$, and mostly (744, $48.4 \%$ ) in the age group 21-30 years old. Residents of Bengaluru city constitute about $35.5 \%$ of the total respondents. About 516 (33.6\%) were isolated with the other three persons. More than one third $(616,40.1 \%)$ of participants spent about 15-20 days in social isolation (Table 1).

Table 1 presents the responses of the participants in the nineitems PHQ-9 questionnaire. In the bivariate analysis there was a significant association between the gender $(P<0.001)$, occupation $(P<0.001)$, age $(P<0.001)$ and location $(\mathrm{p}=$ $0.021)$ and the different severity of depression in the PHQ9.Females showed an increasing trend of mild, moderate, and severe depression compared to their counterparts males. About $50.8 \%$ of females exhibit some degree of depression. About $51.1 \%$ of participants in the age group 21-30 years showed a higher depression trend than other age groups. The undergraduate students and school students have slightly above $50.0 \%$ overall depression than other occupation groups. The major cities, including the Ballari, Belagavi, and Bengaluru, have an average of $40.0 \%$ overall depression than other regions.

Table 2 presents the responses of the participants in the sevenitems GAD-7 questionnaire. There was a significant association between the age $(P=0.016)$ and the different severity of anxiety in the GAD-7 questionnaire in the bivariate analysis. About $45.7 \%$ of the participants in the age group 31-40 years showed a greater prevalence of anxiety than the other age groups.

Table 1 Respondents characteristics on the PHQ questionnaire according to the severity $(n=1537)$ 


\begin{tabular}{|c|c|c|c|c|c|c|c|c|}
\hline Variables & Total & Normal & Mild & Moderate & $\begin{array}{l}\text { Moderately } \\
\text { Severe }\end{array}$ & Severe & $\mathrm{Chi}^{2}$ & $P$-value \\
\hline Gender & & & & & & & 29.960 & $<0.05$ \\
\hline Male & $764(49.7)$ & $436(57.1)$ & $218(28.5)$ & $69(9)$ & $32(4.2)$ & $9(1.2)$ & & \\
\hline Female & $768(50.0)$ & $378(49.2)$ & $246(32)$ & $102(13.3)$ & $25(3.3)$ & $17(2.2)$ & & \\
\hline Others & $5(0.3)$ & $1(20)$ & $1(20)$ & $2(40)$ & $0(0)$ & $1(20)$ & & \\
\hline Occupation & & & & & & & 69.731 & $<0.05$ \\
\hline School student & $31(2)$ & $15(48.4)$ & $9(29)$ & $5(16.1)$ & $2(6.5)$ & $0(0)$ & & \\
\hline UG student & $951(61.9)$ & $434(45.6)$ & $333(35)$ & $122(12.8)$ & $43(4.5)$ & $19(2)$ & & \\
\hline PG student & $56(3.6)$ & $28(50)$ & $16(28.6)$ & $7(12.5)$ & $4(7.1)$ & $1(1.8)$ & & \\
\hline Working professional & $499(32.5)$ & $338(67.7)$ & $107(21.4)$ & $39(7.8)$ & $8(1.6)$ & $7(1.4)$ & & \\
\hline Age & & & & & & & 106.352 & $<0.05$ \\
\hline $10-20$ & $451(29.3)$ & $197(43.7)$ & $159(35.3)$ & $64(14.2)$ & $22(4.9)$ & $9(2)$ & & \\
\hline $21-30$ & $744(48.4)$ & $364(48.9)$ & $246(33.1)$ & $89(12)$ & $32(4.3)$ & $13(1.7)$ & & \\
\hline $31-40$ & $116(7.5)$ & $77(66.4)$ & $23(19.8)$ & $10(8.6)$ & $2(1.7)$ & $4(3.4)$ & & \\
\hline $41-50$ & $102(6.6)$ & $74(72.5)$ & $24(23.5)$ & $4(3.9)$ & $0(0)$ & $0(0)$ & & \\
\hline $51-60$ & $97(6.3)$ & $79(81.4)$ & 11(11.3) & $6(6.2)$ & $1(1)$ & $0(0)$ & & \\
\hline $61-70$ & $19(1.2)$ & $18(94.7)$ & $1(5.3)$ & $0(0)$ & $0(0)$ & $0(0)$ & & \\
\hline $70+$ & $8(0.5)$ & $6(75)$ & $1(12.5)$ & $0(0)$ & $0(0)$ & $1(12.5)$ & & \\
\hline Location & & & & & & & 130.895 & 0.021 \\
\hline Bagalkote & $25(1.6)$ & $13(52)$ & $5(20)$ & $5(20)$ & $1(4)$ & $1(4)$ & & \\
\hline Ballari & $75(4.9)$ & $36(48)$ & $20(26.7)$ & 11(14.7) & $6(8)$ & $2(2.7)$ & & \\
\hline Belagavi & $358(23.3)$ & $187(52.2)$ & $110(30.7)$ & $48(13.4)$ & $8(2.2)$ & $5(1.4)$ & & \\
\hline Bengaluru & $546(35.5)$ & $300(54.9)$ & $162(29.7)$ & $51(9.3)$ & $21(3.8)$ & $12(2.2)$ & & \\
\hline Bhadravati & $1(0.1)$ & $1(100)$ & $0(0)$ & $0(0)$ & $0(0)$ & $0(0)$ & & \\
\hline Bidar & $17(1.1)$ & $9(52.9)$ & $5(29.4)$ & $2(11.8)$ & $0(0)$ & $1(5.9)$ & & \\
\hline Chikkamagaluru & $7(0.5)$ & $4(57.1)$ & $2(28.6)$ & $1(14.3)$ & $0(0)$ & $0(0)$ & & \\
\hline Chitradurga & $67(4.4)$ & $37(55.2)$ & $17(25.4)$ & 11(16.4) & $2(3)$ & $0(0)$ & & \\
\hline Davanagere & $26(1.7)$ & $15(57.7)$ & $9(34.6)$ & $1(3.8)$ & $1(3.8)$ & $0(0)$ & & \\
\hline Gadag-Betageri & $30(2)$ & $15(50)$ & $9(30)$ & $4(13.3)$ & $2(6.7)$ & $0(0)$ & & \\
\hline Gangavati & $17(1.1)$ & $7(41.2)$ & $7(41.2)$ & $3(17.6)$ & $0(0)$ & $0(0)$ & & \\
\hline Hassan & $18(1.2)$ & $10(55.6)$ & $6(33.3)$ & $2(11.1)$ & $0(0)$ & $0(0)$ & & \\
\hline Hosapete & $9(0.6)$ & $2(22.2)$ & $5(55.6)$ & $1(11.1)$ & $0(0)$ & $1(11.1)$ & & \\
\hline Hubli-Dharwad & $52(3.4)$ & $36(69.2)$ & $11(21.2)$ & $3(5.8)$ & $0(0)$ & $2(3.8)$ & & \\
\hline Kalaburagi & $33(2.1)$ & $15(45.5)$ & $15(45.5)$ & $1(3)$ & $2(6.1)$ & $0(0)$ & & \\
\hline Kolara & $16(1)$ & $7(43.8)$ & $9(56.3)$ & $0(0)$ & $0(0)$ & $0(0)$ & & \\
\hline Mandya & $5(0.3)$ & $1(20)$ & $2(40)$ & $2(40)$ & $0(0)$ & $0(0)$ & & \\
\hline Mangaluru & $43(2.8)$ & $25(58.1)$ & $15(34.9)$ & $2(4.7)$ & $1(2.3)$ & $0(0)$ & & \\
\hline Mysuru & $30(2)$ & $11(36.7)$ & 11(36.7) & $5(16.7)$ & $3(10)$ & $0(0)$ & & \\
\hline Raichur & $14(0.9)$ & $5(35.7)$ & $8(57.1)$ & $0(0)$ & $1(7.1)$ & $0(0)$ & & \\
\hline Ranebennuru & $10(0.7)$ & $4(40)$ & $5(50)$ & $0(0)$ & $0(0)$ & $1(10)$ & & \\
\hline Robertsonpete & $1(0.1)$ & $0(0)$ & $0(0)$ & $0(0)$ & $1(100)$ & $0(0)$ & & \\
\hline Shivamogga & $19(1.2)$ & $12(63.2)$ & $3(15.8)$ & $3(15.8)$ & $1(5.3)$ & $0(0)$ & & \\
\hline Tumakuru & $26(1.7)$ & $16(61.5)$ & $8(30.8)$ & $0(0)$ & $2(7.7)$ & $0(0)$ & & \\
\hline Udupi & $25(1.5)$ & $13(52)$ & $6(24)$ & $5(20)$ & $0(0)$ & $1(4)$ & & \\
\hline Vijayapura & $67(4.4)$ & $34(50.7)$ & $15(22.4)$ & $12(17.9)$ & $5(7.5)$ & $1(1.5)$ & & \\
\hline Number of people Isolated with & & & & & & & 25.854 & 0.361 \\
\hline 1 & 123(8) & $67(54.5)$ & $34(27.6)$ & $13(10.6)$ & $5(4.1)$ & $4(3.3)$ & & \\
\hline 2 & $250(16.3)$ & $144(57.6)$ & $70(28)$ & $27(10.8)$ & $5(2)$ & $4(1.6)$ & & \\
\hline 3 & $516(33.6)$ & $257(49.8)$ & $180(34.9)$ & $58(11.2)$ & $12(2.3)$ & $9(1.7)$ & & \\
\hline 4 & $300(19.5)$ & $167(55.7)$ & $82(27.3)$ & $32(10.7)$ & $14(4.7)$ & $5(1.7)$ & & \\
\hline 5 & $157(10.2)$ & $76(48.4)$ & $47(29.9)$ & $23(14.6)$ & $10(6.4)$ & $1(0.6)$ & & \\
\hline 6 & $58(3.8)$ & $34(58.6)$ & $15(25.9)$ & $6(10.3)$ & $2(3.4)$ & $1(1.7)$ & & \\
\hline$>6$ & $133(8.7)$ & $70(52.6)$ & $37(27.8)$ & $14(10.5)$ & $9(6.8)$ & $3(2.3)$ & & \\
\hline Number of days in social isolation & & & & & & & 20.993 & 0.179 \\
\hline $10-15$ & $510(33.2)$ & $295(57.8)$ & $148(29)$ & $53(10.4)$ & $9(1.8)$ & $5(1)$ & & \\
\hline $15-20$ & $616(40.1)$ & $310(50.3)$ & 191(31) & $72(11.7)$ & $31(5)$ & $12(1.9)$ & & \\
\hline $20-25$ & $288(18.7)$ & $148(51.4)$ & $87(30.2)$ & $33(11.5)$ & $12(4.2)$ & $8(2.8)$ & & \\
\hline $25-30$ & $82(5.3)$ & $41(50)$ & $23(28)$ & 13(15.9) & $4(4.9)$ & $1(1.2)$ & & \\
\hline$>30$ & $41(2.7)$ & $21(51.2)$ & $16(39)$ & $2(4.9)$ & $1(2.4)$ & $1(2.4)$ & & \\
\hline
\end{tabular}

Table 2 Respondents characteristics on GAD questionnaire according to the severity ( $\mathrm{n}=1537)$ 


\begin{tabular}{|c|c|c|c|c|c|c|c|}
\hline Variables & Total & Normal & Mild & Moderate & Severe & $\mathrm{Chi}^{2}$ & $P$-value \\
\hline Gender & & & & & & 12.243 & 0.057 \\
\hline Male & $764(49.7)$ & $471(61.6)$ & 199(26) & $69(9)$ & $25(3.3)$ & & \\
\hline Female & $768(50.0)$ & $426(55.5)$ & $245(31.9)$ & $72(9.4)$ & $25(3.3)$ & & \\
\hline Others & $5(0.3)$ & $2(40)$ & $2(40)$ & $0(0)$ & $1(20)$ & & \\
\hline Occupation & & & & & & 14.297 & 0.112 \\
\hline School student & $31(2)$ & $20(64.5)$ & $9(29)$ & $2(6.5)$ & $0(0)$ & & \\
\hline UG student & $951(61.9)$ & $549(57.7)$ & $293(30.8)$ & $81(8.5)$ & $28(2.9)$ & & \\
\hline PG student & $56(3.6)$ & $28(50)$ & $22(39.3)$ & $3(5.4)$ & $3(5.4)$ & & \\
\hline Working professional & $499(32.5)$ & $302(60.5)$ & $122(24.4)$ & $55(11)$ & $20(4)$ & & \\
\hline Age & & & & & & 33.165 & 0.016 \\
\hline $10-20$ & $451(29.3)$ & $265(58.8)$ & $140(31)$ & $34(7.5)$ & $12(2.7)$ & & \\
\hline $21-30$ & $744(48.4)$ & $419(56.3)$ & $228(30.6)$ & $73(9.8)$ & $24(3.2)$ & & \\
\hline $31-40$ & $116(7.5)$ & $63(54.3)$ & $33(28.4)$ & $14(12.1)$ & $6(5.2)$ & & \\
\hline $41-50$ & $102(6.6)$ & $59(57.8)$ & $32(31.4)$ & $7(6.9)$ & $4(3.9)$ & & \\
\hline $51-60$ & $97(6.3)$ & $75(77.3)$ & $8(8.2)$ & $10(10.3)$ & $4(4.1)$ & & \\
\hline $61-70$ & $19(1.2)$ & $14(73.7)$ & $3(15.8)$ & $2(10.5)$ & $0(0)$ & & \\
\hline $70+$ & $8(0.5)$ & $4(50)$ & $2(25)$ & $1(12.5)$ & $1(12.5)$ & & \\
\hline Location & & & & & & 73.763 & 0.519 \\
\hline Bagalkote & $25(1.6)$ & $12(48)$ & $9(36)$ & $2(8)$ & $2(8)$ & & \\
\hline Ballari & $75(4.9)$ & $41(54.7)$ & $24(32)$ & $6(8)$ & $4(5.3)$ & & \\
\hline Belagavi & $358(23.3)$ & $201(56.1)$ & $112(31.3)$ & $35(9.8)$ & $10(2.8)$ & & \\
\hline Bengaluru & $546(35.5)$ & $332(60.8)$ & $148(27.1)$ & 49(9) & $17(3.1)$ & & \\
\hline Bhadravati & $1(0.1)$ & $1(100)$ & $0(0)$ & $0(0)$ & $0(0)$ & & \\
\hline Bidar & $17(1.1)$ & $8(47.1)$ & $8(47.1)$ & $0(0)$ & $1(5.9)$ & & \\
\hline Chikkamagaluru & $7(0.5)$ & $4(57.1)$ & $2(28.6)$ & $1(14.3)$ & $0(0)$ & & \\
\hline Chitradurga & $67(4.4)$ & $48(71.6)$ & $14(20.9)$ & $5(7.5)$ & $0(0)$ & & \\
\hline Davanagere & $26(1.7)$ & $15(57.7)$ & $9(34.6)$ & $2(7.7)$ & $0(0)$ & & \\
\hline Gadag-Betageri & $30(2)$ & $17(56.7)$ & $7(23.3)$ & $5(16.7)$ & $1(3.3)$ & & \\
\hline Gangavati & $17(1.1)$ & $9(52.9)$ & $8(47.1)$ & $0(0)$ & $0(0)$ & & \\
\hline Hassan & $18(1.2)$ & $12(66.7)$ & $4(22.2)$ & $2(11.1)$ & $0(0)$ & & \\
\hline Hosapete & $9(0.6)$ & $4(44.4)$ & $4(44.4)$ & $0(0)$ & $1(11.1)$ & & \\
\hline Hubli-Dharwad & $52(3.4)$ & $38(73.1)$ & $9(17.3)$ & $4(7.7)$ & 1(1.9) & & \\
\hline Kalaburagi & $33(2.1)$ & $16(48.5)$ & $13(39.4)$ & $3(9.1)$ & $1(3)$ & & \\
\hline Kolara & $16(1)$ & $9(56.3)$ & $7(43.8)$ & $0(0)$ & $0(0)$ & & \\
\hline Mandya & $5(0.3)$ & $2(40)$ & $2(40)$ & $1(20)$ & $0(0)$ & & \\
\hline Mangaluru & $43(2.8)$ & $31(72.1)$ & $9(20.9)$ & $1(2.3)$ & $2(4.7)$ & & \\
\hline Mysuru & $30(2)$ & $16(53.3)$ & $6(20)$ & $6(20)$ & $2(6.7)$ & & \\
\hline Raichur & $14(0.9)$ & $8(57.1)$ & $4(28.6)$ & $2(14.3)$ & $0(0)$ & & \\
\hline Ranebennuru & $10(0.7)$ & $4(40)$ & $3(30)$ & $2(20)$ & $1(10)$ & & \\
\hline Robertsonpete & $1(0.1)$ & $0(0)$ & $1(100)$ & $0(0)$ & $0(0)$ & & \\
\hline Shivamogga & $19(1.2)$ & $13(68.4)$ & $3(15.8)$ & $2(10.5)$ & $1(5.3)$ & & \\
\hline Tumakuru & $26(1.7)$ & $9(34.6)$ & $13(50)$ & $3(11.5)$ & $1(3.8)$ & & \\
\hline Udupi & $25(1.5)$ & $12(48)$ & $10(40)$ & $2(8)$ & $1(4)$ & & \\
\hline Vijayapura & $67(4.4)$ & $38(56.7)$ & $16(23.9)$ & $8(11.9)$ & $5(7.5)$ & & \\
\hline Number of people Isolated with & & & & & & 16.707 & 0.543 \\
\hline 1 & $123(8)$ & $70(56.9)$ & $37(30.1)$ & $11(8.9)$ & $5(4.1)$ & & \\
\hline 2 & $250(16.3)$ & $163(65.2)$ & $68(27.2)$ & $12(4.8)$ & $7(2.8)$ & & \\
\hline 3 & $516(33.6)$ & $302(58.5)$ & $153(29.7)$ & $45(8.7)$ & $16(3.1)$ & & \\
\hline 4 & $300(19.5)$ & $176(58.7)$ & $80(26.7)$ & $33(11)$ & $11(3.7)$ & & \\
\hline 5 & $157(10.2)$ & $91(58)$ & $46(29.3)$ & $16(10.2)$ & $4(2.5)$ & & \\
\hline 6 & $58(3.8)$ & $30(51.7)$ & $20(34.5)$ & $6(10.3)$ & $2(3.4)$ & & \\
\hline$>6$ & $133(8.7)$ & $67(50.4)$ & $42(31.6)$ & $18(13.5)$ & $6(4.5)$ & & \\
\hline Number of days in social isolation & & & & & & 14.868 & 0.249 \\
\hline $10-15$ & $510(33.2)$ & $311(61)$ & $134(26.3)$ & $52(10.2)$ & $13(2.5)$ & & \\
\hline $15-20$ & $616(40.1)$ & $358(58.1)$ & $188(30.5)$ & $52(8.4)$ & $18(2.9)$ & & \\
\hline $20-25$ & $288(18.7)$ & $162(56.3)$ & $87(30.2)$ & $23(8)$ & $16(5.6)$ & & \\
\hline $25-30$ & $82(5.3)$ & $50(61)$ & $20(24.4)$ & $9(11)$ & $3(3.7)$ & & \\
\hline$>30$ & $41(2.7)$ & $18(43.9)$ & $17(41.5)$ & $5(12.2)$ & $1(2.4)$ & & \\
\hline
\end{tabular}


In this study, the main goal was to explore quarantine's psychological impact on individuals due to the novel coronavirus pandemic. Our study's findings showed a high prevalence of depression $(722,47.0 \%)$ and anxiety (638, $41.5 \%$ ) among the surveyed sample. There is a significant increase in the number of cases compared to the findings of earlier studies conducted at the beginning of the outbreak in China [9]. Most probably due to the fear instilled in the general population regarding the pandemic, which was not so deeprooted during the study conducted in China and was still in its initial stages.

Considering the socio-demographic factors, depression was further associated with age, gender, location, occupation. Women are more prone to depression than men for many reasons, some of which may be related to the workload of managing the home and taking care of their families [18]. Depression is more common among young women between the ages of 14 and 25 compared to men [19].

Moreover, the age group 21-30 years seems to be more prone to depression because people in this age group are wellversed in using electronics and social media, which makes them strongly affected by rumors and news published by these media sources may not be accurate.

Furthermore, the increasing number of COVID-19 patients caused the suspension of studies at all levels in India and most countries of the world. This may explain the increase in the rate of depression among students due to the extension of isolation, the fear of losing classes, and the inability to administer the upcoming exams after raising the quarantine. Jones [20] said that more than half of the surveyed students had needed mental health services since the schools closed after the COVID-19 outbreak.

The results of the study showed a high prevalence of anxiety among the respondents in the age group 21-50 years, which reflects the impact of the economic crisis on mental health among the working population Frasquilho et al. [21] concluded that economic recession, unemployment, low income, and debt are raising the rates of common mental disorders, substancerelated disorders, and suicidal behavior.

Moreover, the extension of quarantine for a long period leads to adopting unhealthy lifestyles such as addiction to electronic devices and a lack of physical activities, thus exacerbating physical, psychological, and social problems [22]. The participants from Belagavi and Bengaluru seem to indicate a high level of depression. These two cities are the major urban sectors of Karnataka and are responsible for a significant economic yield of the state and house most of the population [23]. Lack of job and business opportunities due to the lockdown can be attributed to increased depression and anxiety among the population.

This study complained of some limitations. The sample was collected through an online questionnaire; hence only people with internet access and understanding of the English language could be a possible volunteer. The psychological effect of the novel coronavirus and isolation in rural internet deprived areas and the unemployed sector may differ from our study as they could not be part of it. Non-uniform distribution of data was received. However, this study may highlight a few significant findings. First, the investigation about the depression and anxiety came early through an online survey conducted in the second and third weeks of the government of India announced. Second, along with other studies, our results will hopefully help in charting out the necessary mental health programs required to address the effects of the Coronavirus outbreak.

Conclusion
In conclusion, this study noticed significant anxiety and depression in the community, responding to an infectious disease outbreak. About $41.5 \%$ of Karnataka's general population has anxiety, and $46.8 \%$ have depression due to the COVID 19 outbreak. The females are more depressed compared to the other genders considered in the study. The age group of 21-30 years was more depressed, while 31-40 years suffer more from anxiety than other age groups. The undergraduate students and people residing in urban areas show a higher rate of depression. The association of anxiety and depression with younger age and female gender may allow identification of the population at risk of psychological disorder during the COVID19 pandemic and the need to address them at an individual and community level.

\section{Abbreviation}

COVID-19: Coronavirus Disease-19; PHQ-9: Patient Health Questionnaire-9; GAD-7: General Anxiety Disorder-7; M: Mean; SD: Standard Deviation; SPSS: Statistical Package for Social Science

\section{Acknowledgment}

We would like to thank Mrs. Sunanda Halki, Dr. Prithvick BG, Dr. Pooja Kulkarni, Dr. Sayed Quadri, Mr. Utkarsh Alok for their guidance, and Ms. Preethi MB, Mrs. Qurathulain Desai, Mr. Jaffar Desai, Mr. Sayed Mohuideen Quadri, Ms. Zoha Desai, Dr. Seema Saleha, Dr. Hameedur Rahman Khan, Dr. Rohini Kulkarni, Dr. Shridhar Kulkarni, Mrs. Sushma Hegde, Mr. Shrikanth Hegde for their valuable help. We would also like to thank all the participants for their responses and the Belagavi institute of medical sciences for their ethical valuation.

\section{Funding}

The authors received no financial support for the research, authorship, and/or publication of this article.

Availability of data and materials

Data will be available by emailing zaiddesai99@yahoo.com.

\section{Authors' contributions}

Mohammed Zaid Jaffar Desai (MZJD) is the principal and responsible investigator of the study who designed the study and coordinated all aspects of the research, including all manuscript preparation steps. Rutuja Kulkarni (RK) and Bhoomika Hegdea (BH) contributed to data collection, drafting the work, writing the manuscript, and reviewed. Atiqur Rahman Khan (ARK) contributed to the conceptualization, analysis, and interpretation of data, drafting the work, and review. All authors read and approved the final manuscript.

Ethics approval and consent to participate

We conducted the research following the Declaration of Helsinki, and the protocol was approved by the Ethics Committee of the Belagavi Institute of Medical Sciences, Rajiv Gandhi University of Health Sciences, India (Ref: BIMS-IEC/97/2020-21).

Consent for publication

Not applicable

Competing interest

The authors declare that they have no competing interests.

Open Access

This article is distributed under the terms of the Creative Commons $\begin{array}{llll}\text { Attribution } & 4.0 & \text { International }\end{array}$ (http://creativecommons.org/licenses/by/4.0/), which permits unrestricted use, distribution, and reproduction in any medium, 
provided you give appropriate credit to the original author(s) and the source, provide a link to the Creative Commons license, and indicate if changes were made. The Creative Commons Public Domain Dedication waiver (http://creativecommons.org/publicdomain/zero/1.0/) applies to the data made available in this article unless otherwise stated.

\section{Author Details}

${ }^{1}$ Department of Community Medicine, Undergraduate, Belagavi Institute of Medical Sciences, Belagavi, Karnataka, India. ${ }^{2}$ Department of Mechanical Engineering, Undergraduate, BMS College of Engineering, Bangalore, Karnataka, India

\section{Article Info}

Received: 19 July 2020

Accepted: 01 September 2020

Published: 23 September 2020

\section{References}

1. World Health Organization, Novel Coronavirus (2019-nCoV) Situation Report -1, 21 January 2020. Available from: https://www.who.int/docs/default-source/coronaviruse/situationreports/20200121-sitrep-1-2019-ncov.pdf, [Accessed on 30 August 2020].

2. Wang C, Pan R, Wan X, Tan Y, Xu L, Ho CS, Ho RC. Immediate Psychological Responses and Associated Factors during the Initial Stage of the 2019 Coronavirus Disease (COVID-19) Epidemic among the General Population in China. Int J Environ Res Public Health. $2020 \quad$ Mar $\quad 6 ; 17(5): 1729$. https://doi.org/10.3390/ijerph17051729.

3. World Health Organization, WHO Director-General's opening remarks at the media briefing on COVID-19 - 11 March 2020. Available from: https://www.who.int/dg/speeches/detail/whodirector-general-s-opening-remarks-at-the-media-briefing-oncovid-19---11-march-2020 [Accessed on 13 April 2020]

4. Coronavirus in India: Latest Map and Case Count. Available from: https://www.covid19india.org/ [Accessed 13 April 2020].

5. Arakal RA. First COVID-19 case in Karnataka: Techie who returned to Bengaluru from US tests positive, (9 March2020). Available from: https://indianexpress.com/article/cities/bangalore/coronaviruskarnataka-first-case-covid-19-bengaluru-6307223/ [Accessed on 13 April 2020]

6. India Today on 24 March 2020. Modi announces lockdown Updates: No panic buying please. Stay indoors, tweets PM. Available from: https://www.indiatoday.in/india/story/pm-modiaddress-the-nation-at-8-pm-today-speech-covid-19-coronaviruslive-updates-1659215-2020-03-24 [Accessed on 13 April 2020]

7. Ali Jadoo SA. Was the world ready to face a crisis like COVID19? Journal of Ideas in Health2020;3(1):123-4. https://doi.org/10.47108/jidhealth.Vol3.Iss1.45

8. Steptoe A, Shankar A, Demakakos P, Wardle J. Social isolation, loneliness, and all-cause mortality in older men and women. Proc Natl Acad Sci U S A. 2013;110(15):5797-5801. https://doi.org/10.1073/pnas.1219686110

9. Cao W, Fang Z, Hou G, Han M, Xu X, Dong J, et al. The psychological impact of the COVID-19 epidemic on college students in China. Psychiatry Res. 2020; 287:112934. https://doi.org/10.1016/j.psychres.2020.112934

10. Taylor HO, Taylor RJ, Nguyen AW, Chatters L. Social Isolation, Depression, and Psychological Distress Among Older Adults. Journal of Aging and Health2018; 30(2): 229-246. https://doi.org/10.1177/0898264316673511

11. Sim K, Huak Chan Y, Chong PN, Chua HC, Wen Soon S. Psychosocial and coping responses within the community health care setting towards a national outbreak of an infectious disease. J Psychosom Res. 2010;68(2):195-202 https://doi.org/10.1016/j.jpsychores.2009.04.004
12. Roy D, Tripathy S, Kar SK, Sharma N, Verma SK, Kaushal V. Study of knowledge, attitude, anxiety \& perceived mental healthcare need in Indian population during COVID-19 pandemic. Asian J Psychiatr. 2020; 51:102083. https://doi.org/10.1016/j.ajp.2020.102083.

13. Karnataka Population. Available from: http://www.populationu.com/in/karnataka-population [Accessed on 8 April 2020]

14. Sample Size Calculator: Understanding Sample Sizes. Available from: https://www.surveymonkey.com/mp/sample-size-calculator/ [Accessed on 5 March 2020]

15. Toussaint A, Hüsing $\mathrm{P}$, Gumz A, Wingenfeld $\mathrm{K}$, Härter $\mathrm{M}$, Schramm E, Löwe B. Sensitivity to change and minimal clinically important difference of the 7-item generalized anxiety disorder questionnaire (GAD-7). J Affect Disord. 2020; 265:395-401. https://doi.org/10.1016/j.jad.2020.01.032

16. Williams N. The GAD-7 Questionnaire [Review of the test Generalized anxiety disorder (gad-7) Questionnaire, by R. L. Spitzer]. Occupational Medicine2014; 64(3): 224. https://doi.org/10.1093/occmed/kqt161

17. Kroenke K, Spitzer RL, Williams JB. The PHQ-9: validity of a brief depression severity measure. $\mathrm{J}$ Gen Intern Med. 2001;16(9):606-613. https://doi.org/10.1046/j.15251497.2001.016009606.

18. Albert PR. Why is depression more prevalent in women? J Psychiatry Neurosci. 2015;40(4):219-221. https://doi.org/10.1503/jpn.150205

19. Patten SB, Wang JL, Williams JV, Wang JL, McDonald K, Bulloch ACM. Descriptive epidemiology of major depression in Canada. Can J Psychiatry. 2006; 51:84-90. https://doi.org/10.1177/070674371506000106

20. Jones C. Student anxiety, depression increasing during school closures, survey finds. EdSorce, 13 May 2020. Available from: https://edsource.org/2020/student-anxiety-depression-increasingduring-school-closures-survey-finds/631224 [Accessed on 29 August 2020].

21. Frasquilho D, Matos MG, Salonna F, Guerreiro D, Storti CC, Gaspar T, Caldas-de-Almeida JM. Mental health outcomes in times of economic recession: a systematic literature review. BMC Public Health2015; 16:115. https://doi.org/10.1186/s12889-0162720-y.

22. Ali Jadoo SA. COVID -19 pandemic is a worldwide typical Biopsychosocial crisis. Journal of Ideas in Health2020;3(2):152-4. https://doi.org/10.47108/jidhealth.Vol3.Iss2.58

23. Prabhu N. Bengaluru urban tops state in per capita income, Kalaburagi last, (20 March 2016). Available from: https://www.thehindu.com/news/cities/bangalore/bengaluruurban-tops-state-in-per-capita-income-kalaburagilast/article8376124.ece [Accessed 13 April 2020]. 